\title{
Assessment of RC Bridges integrity by means of low-cost investigations
}

\author{
Flavio Stochino, Maria Luisa Fadda, Fausto Mistretta \\ Department of Civil Environmental Engineering and Architecture University of Cagliari \\ fstochino@unica.it, bttp://orcid.org/0000-0002-0786-9070 \\ mary.fadda@tiscali.it \\ fmistret@unica.it, http://orcid.org/0000-000 2-5238-7644
}

ABSTRACT. Infrastructure aging is an important problem nowadays, in particular for countries like Italy in which the main motorways were built 50 years ago. Huge budgets are necessary to keep infrastructure and bridges in service. In addition, the lack of a proper and timely maintenance, entails an increase of the deterioration and therefore higher costs of repair.

Thus, the need of methods capable of assessing the reliability of the infrastructure in the frame of Bridge Management System (BMS), is patent.

The aim of this work is to provide a robust decision-support tool for the analysis of the data collected with field inspection. The innovative aspect of the proposal is the introduction of two factors which take into account the location of the damage, and the mechanical characterization of the material in the definition of a Condition Rating Number (CRN).

The analysis of an existing Reinforced Concrete (RC) bridge network is presented in order to show the accuracy of this new method.

KEYwORDS. Bridges; Concrete; BMS; Durability; Inspection; Maintenance.

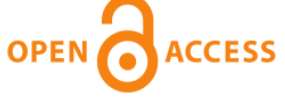

Citation: Stochino, F., Fadda, M.L., Mistretta, F. Assessment of RC Bridges deterioration by means of low-cost investigations, Frattura ed Integrità Strutturale, 46 (2018) 216-225.

Received: 27.07 .2018

Accepted: 31.08 .2018

Published: 01.10.2018

Copyright: (C) 2018 This is an open access article under the terms of the CC-BY 4.0, which permits unrestricted use, distribution, and reproduction in any medium, provided the original author and source are credited.

\section{INTRODUCTION}

1 he wear of an asset due to its prolonged use results in a gradual degradation of its performance. The aging of materials and asset technology yields to a decline in technical efficiency or technological obsolescence.

Chemical-physical tests have a fundamental role in the inspection and maintenance of installations and machines, see [1-2]. The continuous measurement of these quantities with automatic or semi-automatic methods allows to know the system state and can provide essential information for the policies on condition assessment from the maintenance point of view, see [3].

The same approach should be applied to concrete bridges networks. In fact, as well as industrial machines and equipment should be monitored continuously, also infrastructures require stringent inspections at regular intervals of all the elements. 
The main objectives of the bridges infrastructure networks maintenance strategies, are to ensure, in probabilistic terms, the safety of the individual citizen and the effectiveness of the transport system. In addition, in case of natural disasters (floods, earthquakes, etc.) or acts of terrorism, a good ability of infrastructural network to provide alternative routes (resilience), with primary focus on strategic activities (civil defense, hospitals, energy supply, waste disposal, etc.) see [4-6], is expected.

In recent years, the importance of Bridge Management System (BMS) has been increasing. BMS is the set of inspection, investigation, maintenance, repair of a group of bridges or viaducts, organized according to priority, with the support of computer databases and algorithms officers. In most of cases, the condition of a structure is assessed by qualitative judgments.

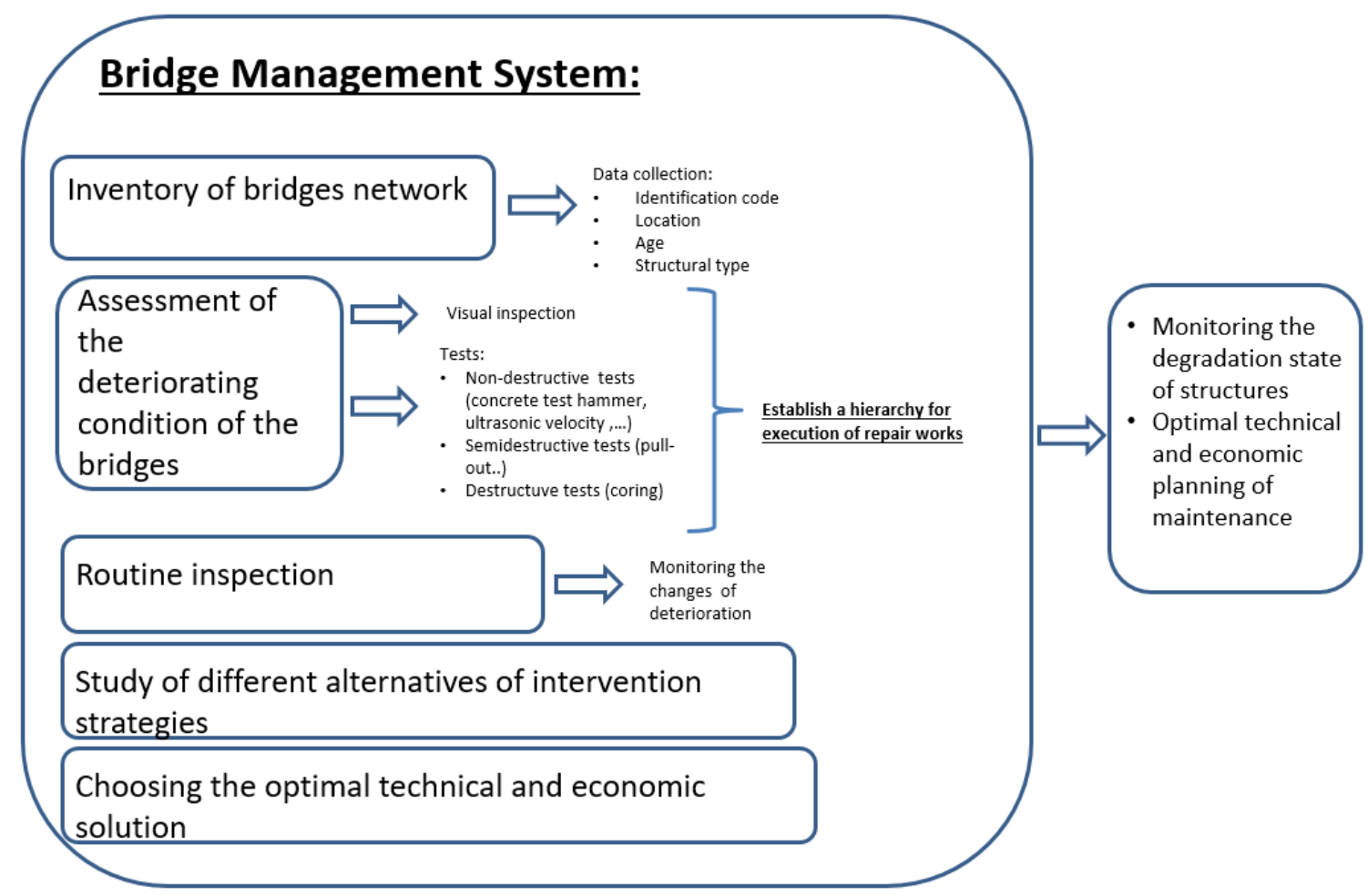

Figure 1: Bridge Management System

In a schematic way, see Fig. 1, it can be said that a BMS is composed of:

- Inventory of bridges network;

- Data analysis capabilities on the basis of deterioration models;

- Cost models;

- Optimization programs, which are based on previous assessments, help in planning characteristics and schedule of the retrofitting.

Therefore, A BMS can be seen as a tool that can:

o Assess the condition and give an overview about the status of the structures;

o Formulate maintenance programs within predetermined cost limits and plan consequent actions;

o Schedule requests and fund appropriations.

The main goal is to obtain a representative picture of each structure that will allow making adequate maintenance work or to underline the need for further in-depth investigation [7].

In order to prioritize maintenance investments bridge rating strategy is adopted in BMS. Usually, the rates of bridges can be compared at project or network level and can consider both serviceability and relevance. Different methods can be found in the literature: an Integrated Bridge Index (IBI) is presented in [8]. It takes into account the vulnerability risk and strategic importance of each net component. Visual inspection, experts survey and regression analysis has been adopted for calibration. An effective approach for fast and automatic evaluation of bridges robustness and resilience is presented in [9], while multi-attribute utility theory (MUAT) is implemented in bridges ranking strategy in [10]. Also fuzzy logic has been adopted in this context with some interesting results, see [11] and [12]. 
The concept that a condition rating method should be based on numerical evaluation of all those essential damage types revealed during inspection has been introduced in [13] by Znidaric and Perus. Variations and applications of this approach has been published in the last years (see [14-16]).

The authors proposed in [17] an improved version of the above-mentioned method which takes into account the mechanical degradation of materials and the location of the damages.

In the present paper an application of this innovative method is described considering a net of bridges in Sardinia (Italy). After a synthetic description of the proposed method the real case-study is analysed with the aim of proving the efficacy of the proposed approach. Finally, some perspectives and conclusive remarks are presented.

\section{Proposed Method}

he proposed method is divided in three main steps:

- thorough visual examinations aimed at detecting any damages in the structure.

- Development of non-destructive tests in order to assess the mechanical characteristics of materials.

- $\quad$ Evaluation of the Condition Rating Number CRN for each structure.

$C R N$ is a non-dimensional number representing the damage degree of the analysed structure. It is defined by the following equation:

$$
C R N=\gamma\left(\frac{\sum_{m=1}^{k} F_{D m}}{\sum_{m=1}^{k} F_{D, r f m}}\right) \cdot 100
$$

where $\gamma$ denotes an arbitrary scale constant that should be tuned for the considered case; $F_{D m}$ represents the condition rating number for the m-th-structural component and $F_{D, r e f m}$ is the corresponding maximum value.

$F_{D m}$ is defined as follows:

$$
F_{D m}=K_{m} \sum_{i=1}^{n} B_{i} \cdot K_{2 i} \cdot K_{3 i} \cdot L_{i} \cdot T_{i}
$$

$K_{m}$ denotes the importance of the considered element into the structure. Its value spans between 0.1 and 1.2. For the sake of synthesis the complete description is not reported here. The interested reader can find the table with all values in [13] Tab. A2 or in [17].

$B_{i}$ denotes the basic value associate to the type of defect " $\mathrm{i}$ ". It expresses the potential effect of the damage type "i" on the safety and / or durability of the element observed. It varies between 1 and 4, see [13] Tab. A1.

The magnitude of the $\mathrm{i}$-th damage is expressed by $K_{2 i}$. Its values range between 0.5 and 2.0 , the complete definition is reported in [13] Tab. A3.

$K_{3 i}$ quantifies the extension of the damage along the structural element, as a number within the range $0-1$ according to the indications reported in [13] Tab. A4.

\begin{tabular}{cc}
\hline Criterion & $\mathrm{L}_{\mathrm{i}}$ \\
Damage not in a critical point & 1 \\
Damage in a critical point & 2 \\
\hline
\end{tabular}

Table 1: $L_{i}$ parameter values representing the damages location importance.

The main novelty of this method is the specification of the damage location and of the material properties degradation in each structural element. These two aspects can be respectively measured by $L_{i}$ and $T_{i}$.

$L_{i}$ denotes the position of the $\mathrm{i}$-th damage in the structural element and it can assume binary values: 1 in case it is not a critical point, 2 if it is a critical point as reported in Tab. 1. Critical points are the parts of the single element that are "critical" for the structural safety. 
The material degradation is represented by $T_{i}$ whose values are reported in the following Tab. 2 . They depend on the ratio between the design material strength $f_{m k d}$ and the one measured by experimental tests developed on site: $f_{m k e x p}$ (e.g. coring strength test, ultrasound pulse test, rebound index etc.). If it is not possible to obtain the design material strength, it is assumed equal to the minimum value required for the considered exposure class (see [18]). In case it is not possible to develop any experimental test on the structural element a conservative value of $T_{i}$ is 4 .

Considering composite structures (e.g. RC) $f_{m k}$ represents the matrix (concrete) compressive cylindrical strength as a first approximation. If it is possible to have information on the reinforcements too it is the averaged mean of the matrix (concrete) and reinforcements (steel) mechanical properties as presented in Eqn. (3):

$$
f_{m k}=f_{c k}+f_{y k} \cdot \frac{E_{c}}{E_{s}}
$$

where $E_{c}$ and $f_{c k}$ respectively are the concrete Young's modulus and characteristic strength, while $E_{s}$ and $f_{y k}$ are the ones corresponding to steel. Eqn. (3) gives $f_{m k^{e x p}}$, when the experimental mechanical characteristics are considered and $f_{m k^{d}}$ when the materials design values are used.

\begin{tabular}{ccc}
\hline Criterion & $f_{m k^{e x p} / f_{m k^{d}}}$ & $T_{i}$ \\
High resistance & $>1$ & 1 \\
Poor resistance & from 0.66 to 1 & 2 \\
Low resistance & from 0.33 to 0.66 & 3 \\
No resistance & from 0 to 0.33 & 4 \\
\hline
\end{tabular}

Table 2: Material characteristics degradation: $T_{i}$ values.

Each structure component should be investigated rating any defects in order to provide a characteristic $F_{d m}$ and $F_{D, r e f m}$, see Eqn. (2). Then the whole structure can be denoted by the value of $C R N$ defined by Eqn. (1). According to this value the structure can included into one of the 4 damage categories presented in Tab. 3. A higher value corresponds to a worst condition and vice versa.

\begin{tabular}{cc}
\hline Damage categories & $\mathrm{CRN} / \gamma$ \\
In service & $0.00-1.36$ \\
Little deterioration & $1.36-1.86$ \\
Severe deterioration & $1.86-2.27$ \\
Urgent intervention & $2.27-2.95$ \\
Out of service & $>2.95$ \\
\hline
\end{tabular}

Table 3: Damage categories for the proposed method.

\section{Application to a REAL CASE-STUdy} every one: a horizontal slab supported by transverse and longitudinal beams simple supported by the lateral abutments, see Figs. 2-4. 


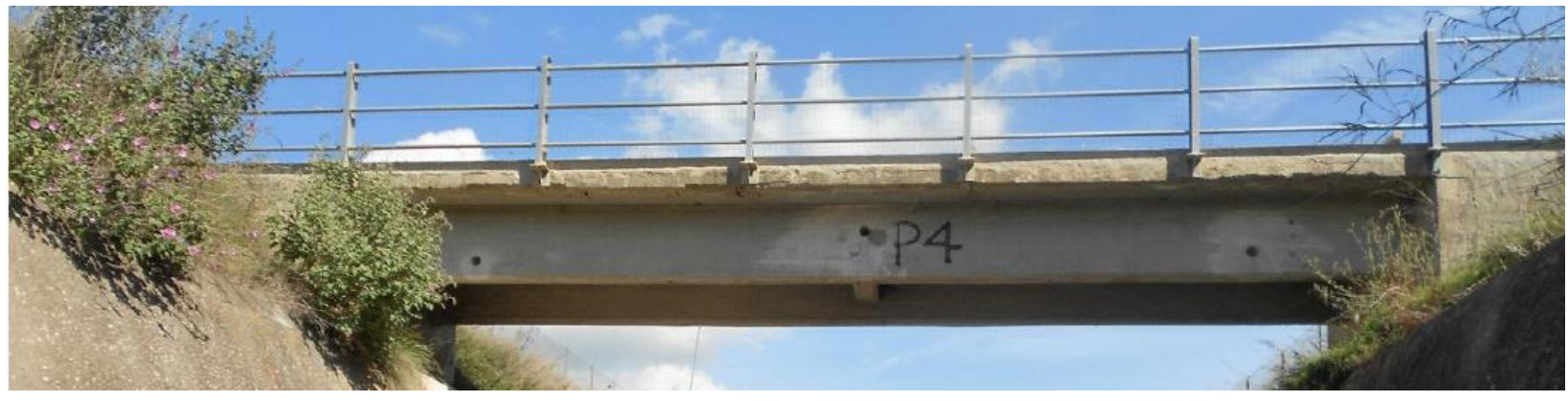

Figure 2: T1 type bridge.

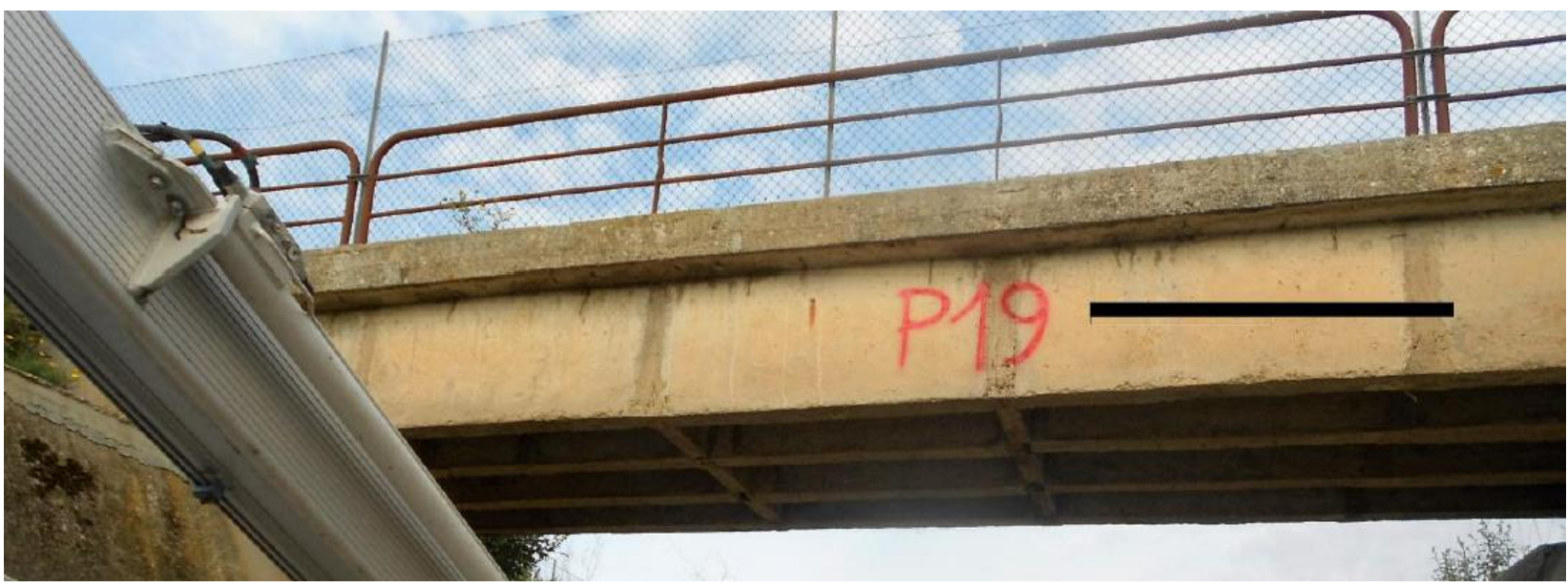

Figure 3: T2 type bridge.

Considering the number of the transverse and longitudinal beams the bridges can be divided in three types as reported in Tab. 4.

The design material resistance is not available, thus given the exposure class XC4, see [18], the minimum resistance class was assumed as the material strength reference class C30/37. For the sake of simplicity, the scale constant $\gamma$ has been considered equal to one.

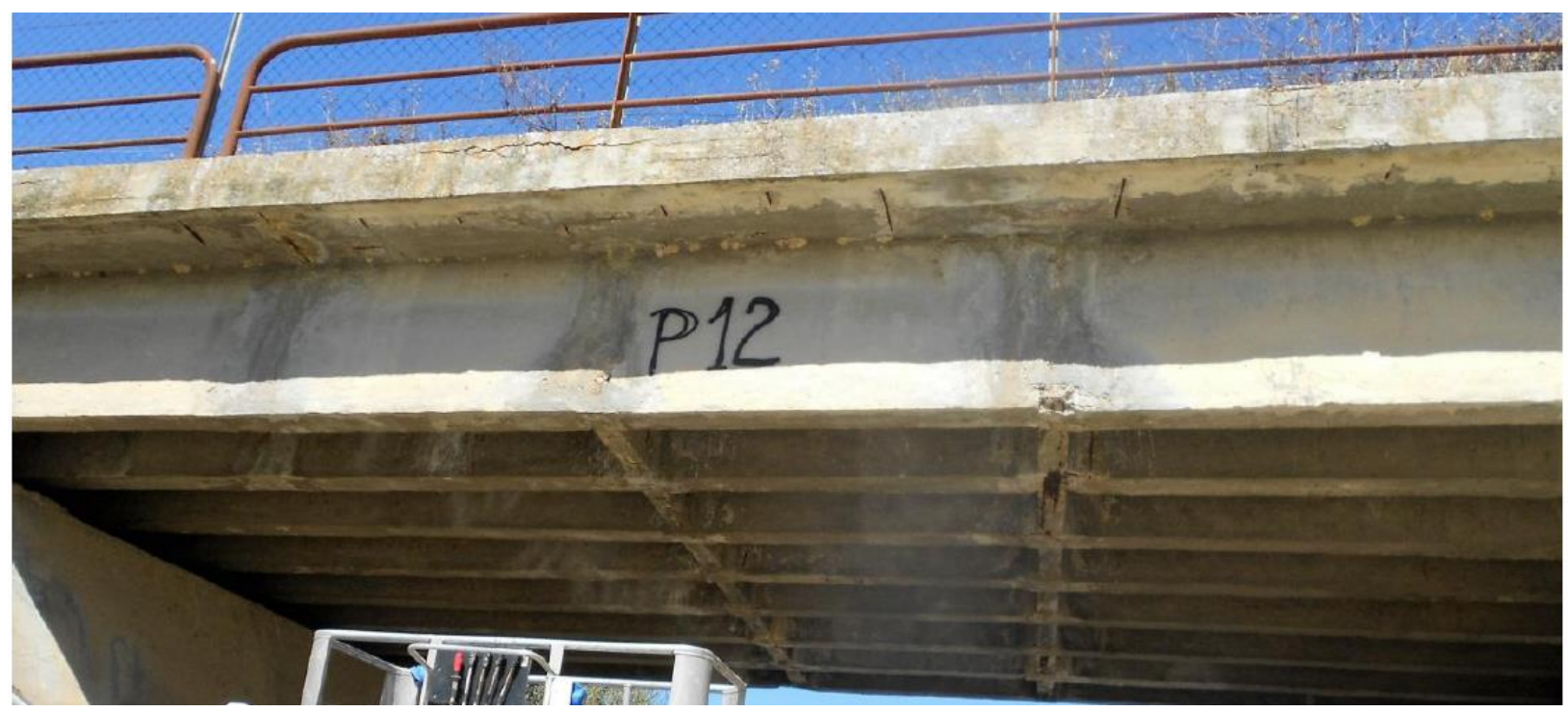

Figure 4: T3 type bridge. 


\begin{tabular}{cccc}
\hline Label & Long. Beam & Transv. Beam & Type \\
P01 & 2 & 1 & T1 \\
P03 & 2 & 1 & T1 \\
P07 & 2 & 1 & T1 \\
P08 & 2 & 1 & T1 \\
P10 & 4 & 2 & T2 \\
P12 & 8 & 2 & T3 \\
P13 & 8 & 2 & T3 \\
\hline
\end{tabular}

Table 4: Bridge net description.

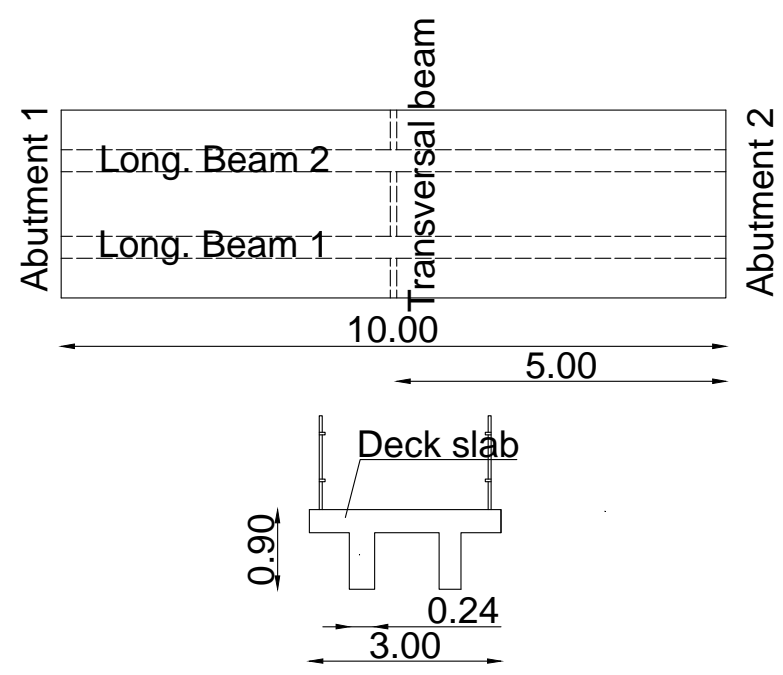

Figure 5: P08 Bridge Structural Scheme.

A set of destructive and not destructive tests (core compressive strength test, sclerometer, pull out, ultrasound wave velocity test, ecc) has been developed on each bridge.

For the sake of synthesis, the average concrete resistance class obtained by the experimental results for each group is reported in the following Tab. 5. This simplification is possible because bridges belonging to the same type are quite homogeneous. In general, bigger bridges (type T3-T2) present better mechanical characteristics in comparison to smaller ones (type T1).

\begin{tabular}{cc}
\hline Bridge Type & Concrete Class \\
T1 & C16/20 \\
T2 & C25/30 \\
T3 & C25/30 \\
\hline
\end{tabular}

Table 5: Concrete class for each bridge group.

In order to show the method, consider the case of bridge P08 that belongs to T1 type. Fig. 5 presents its geometrical dimensions and structural scheme. The visual inspection enriched by the experimental tests produced a damage identification form for each structural component. Some examples for abutment, beam and slab are reported in Tab. 6-8. Also, the value of location coefficient $L_{i}$ and material degradation coefficient $T_{i}$ are reported in these tables.

Humidity spot have been detected in every structural component, concrete spalling is present in the abutments and in the slab. Some transversal cracks are present in the longitudinal beams. Most of damages were not located in critical points $\left(L_{i}=1\right)$ while the information on materials yield to a value of $T_{i}=3$ for the whole bridge. 


\begin{tabular}{|c|c|c|c|c|c|c|c|}
\hline Damage & $\mathrm{B}$ & $\mathrm{K}_{2}$ & $\mathrm{~K}_{3}$ & $\mathrm{~L}_{\mathrm{i}}$ & $\mathrm{R}_{\mathrm{ck}} \exp$ & $\mathrm{R}_{\mathrm{ck}}{ }^{\mathrm{d}}$ & $\mathrm{T}_{\mathrm{i}}$ \\
\hline Humidity spot & 1 & 1.5 & 1.5 & 1 & 20 & 37 & 3 \\
\hline Deteriorated Concrete & 1 & 1.5 & 1.5 & 1 & & & \\
\hline Spalling & 2 & 1 & 0.5 & 1 & & & \\
\hline Rusted reinforcements & 3 & 1 & 0.5 & 1 & & & \\
\hline Web fracture & 1 & & & & & & \\
\hline Horizontal cracks & 1 & & & & & & \\
\hline Vertical cracks & 3 & & & & & & \\
\hline Inclined cracks & 3 & & & & & & \\
\hline Rusted stirrups & 3 & 1 & 0.5 & 1 & & & \\
\hline Deformed reinforcements & 4 & & & & & & \\
\hline Construction joint deterioration & 1 & & & & & & \\
\hline Impact damages & 1 & & & & & & \\
\hline Support damages - top edge & 2 & & & & & & \\
\hline $\begin{array}{c}\text { Support damages - bottom } \\
\text { edge }\end{array}$ & 4 & & & & & & \\
\hline Out of plumb & 2 & & & & & & \\
\hline
\end{tabular}

Table 6: Abutment Damage identification form for Bridge P08.

\begin{tabular}{|c|c|c|c|c|c|c|c|}
\hline Damage & B & $\mathrm{K}_{2}$ & $\mathrm{~K}_{3}$ & $\mathrm{~L}_{\mathrm{i}}$ & $\mathrm{R}_{\mathrm{ck}} \exp$ & $\mathrm{R}_{\mathrm{ck}}{ }^{\mathrm{d}}$ & $\mathrm{T}_{\mathrm{i}}$ \\
\hline Humidity spot & 1 & 1 & 1.5 & 1 & 20 & 37 & 3 \\
\hline Deteriorated Concrete & 1 & & & & & & \\
\hline Beam/Slab joint deterioration & 2 & & & & & & \\
\hline Freezing & 2 & & & & & & \\
\hline De-icing salts & 2 & & & & & & \\
\hline Spalling & 2 & 2 & 2 & 1 & & & \\
\hline Reinforcements corrosion & 3 & 2 & 2 & 1 & & & \\
\hline Tendons corrosion & 4 & & & & & & \\
\hline Duct deficiency & 2 & & & & & & \\
\hline Web fracture & 1 & & & & & & \\
\hline Longitudinal cracks & 3 & & & & & & \\
\hline Vertical cracks & 3 & 1.5 & 1.5 & 2 & & & \\
\hline Inclined cracks & 3 & & & & & & \\
\hline Rusted stirrups & 3 & 2 & 2 & 1 & & & \\
\hline Deformed reinforcements & 4 & & & & & & \\
\hline Construction joint deterioration & 2 & & & & & & \\
\hline Impact damages & 1 & & & & & & \\
\hline
\end{tabular}

Table 7: Longitudinal beam damage identification form for Bridge P08. 


\begin{tabular}{lccccccc}
\hline \multicolumn{1}{c}{ Damage } & $\mathrm{B}$ & $\mathrm{K}_{2}$ & $\mathrm{~K}_{3}$ & $\mathrm{~L}_{\mathrm{i}}$ & $\mathrm{R}_{\mathrm{ck}} \mathrm{exp}$ & $\mathrm{R}_{\mathrm{ck}} \mathrm{d}^{2}$ & $\mathrm{~T}_{\mathrm{i}}$ \\
Humidity spot & 1 & 2 & 2 & 2 & 20 & 37 & 3 \\
Deteriorated Concrete & 1 & 2 & 1.5 & 1 & & \\
Spalling & 2 & 2 & 1.5 & 1 & & \\
Reinforcements corrosion & 3 & 1.5 & 1.5 & 1 & & \\
Web fracture & 1 & & & & & \\
Longitudinal cracks & 3 & & & & & \\
Vertical cracks & 3 & & & & & \\
Inclined cracks & 3 & & & & & \\
Rusted stirrups & 3 & 2 & 1.5 & & & \\
Construction joint deterioration & 3 & & & & \\
\hline
\end{tabular}

Table 8: Slab Damage identification form for bridge P08.

The values of Km, see Eqn. (2), are: abutment 0.4, slab 0.4, longitudinal beam 0.6, transversal beam 0.3. Tab. 9 presents the damage analysis for each structural component. For the specific case it is clear that the Longitudinal beam 1 and the slab are the most damaged elements.

\begin{tabular}{llll}
\hline Element & $F_{\mathrm{dm}}$ & $F_{\mathrm{D}, \mathrm{refm}}$ & $100 \mathrm{~F}_{\mathrm{dm}} /$ FD,refm \\
Abutment 1 & 10.20 & 512 & 1.99 \\
Abutment 2 & 4.80 & 512 & 0.94 \\
Slab & 39.30 & 320 & 12.28 \\
Lon.Beam 1 & 84.60 & 480 & 17.62 \\
Lon.Beam 2 & 31.95 & 480 & 6.65 \\
Transv.Beam & 0.0 & 240 & 0.00 \\
\hline
\end{tabular}

Table 9: Damage estimation for bridge P08 components.

\begin{tabular}{lll}
\hline Order of urgency & Bridge Label & CRN \\
$1^{\circ}$ & P13 & 10.51 \\
$2^{\circ}$ & P12 & 8.98 \\
$3^{\circ}$ & P07 & 8.06 \\
$4^{\circ}$ & P08 & 6.72 \\
$5^{\circ}$ & P10 & 2.95 \\
$6^{\circ}$ & P03 & 0.63 \\
\hline
\end{tabular}

Table 10: Intervention order within the infrastructure network. 
The global CNR for bridge P08 is 6.72, it requires immediate retrofitting. In particular, the above mentioned structural component should be analysed with higher accuracy in order to control the damage evolution and design the refurbishments operations.

The same procedure can be applied to all other bridges and Tab. 10 presents the synthetic results of the whole net assessment. Bridge P13, P12, P07, P08 require immediate retrofitting, while P10 is in service even with urgent maintenance needs. Only bridge P01 and P03 are in good condition.

It is clear that this result can represent a starting point for the bridge net condition assessment. Further investigations are advised for the bridges that require urgent or immediate retrofitting in order to design the necessary refurbishments.

\section{CONCLUSIONS}

T $\mathrm{n}$ this paper the application of a new method for fast and low-cost condition rating mark for RC bridge network has been described.

This method is based on visual inspection and experimental on-site tests. It can be briefly described by the following steps:

- Identification of the structural components of each bridge (or construction).

- Weighting of each structural component for the whole structure safety.

- $\quad$ Visual inspection, experimental testing (if possible), information collection.

- $\quad$ Rating of each damage considering importance, extension and magnitude, position and material degradation.

- $\quad$ Ranking of the structures belonging to the same net using Eqns. (1) - (2).

This rank can help BMS decision makers in optimizing the allocation of available funds for maintenance and management costs (service interruption etc).

Main innovations of this approach are the parameters that take into account the location of the damage at the structural elements level and the mechanical degradation of materials.

The application to a real case study proved the efficacy of this method giving an "urgency ranking" for retrofitting needs of a bridge net, but also a priority list of damaged elements among the same structure. In particular, during the structure life time [19], it is possible to "track" damages evolution creating an useful specific database.

Further developments are expected implementing the approach in an automatized algorithm that is capable of assessing the bridge condition using an inverse problem approach, [20]. In addition, the authors would like to extend the method to different kinds of materials (like steel, masonry) and other types of constructions (e.g. general buildings).

\section{REFERENCES}

[1] Carvalho, H., Hallal Fakury, R. and Leite Vilela, P. (2017). Structural integrity assessment and rehabilitating of Hercilio Luz bridge. Frattura ed Integrità Strutturale, 11(42), pp. 93-104. DOI: 10.3221/IGF-ESIS.42.11.

[2] Berto, F., Razavi, J., Jones, R. and Peng, D. (2018). Effect of corrosion and fatigue on the remaining life of structures and its implication to additive manufacturing. Frattura ed Integrità Strutturale, 12(45), pp. 33-44.

DOI: 10.3221/IGF-ESIS.45.03.

[3] Furlanetto, L., Garetti, M. and Macchi, M. (2007). Ingegneria della manutenzione. Strategie e metodi. Milano: Franco Angeli.

[4] Stochino, F. and Carta, G. (2014). SDOF models for reinforced concrete beams under impulsive loads accounting for strain rate effects. Nuclear Engineering and Design, 276, pp.74-86. DOI: 10.1016/j.nucengdes.2014.05.022

[5] Stochino, F. (2016). RC beams under blast load: Reliability and sensitivity analysis. Engineering Failure Analysis, 66, pp.544-565. DOI: 10.1016/j.engfailanal.2016.05.003

[6] Stochino, F., Mistretta, F., Meloni, P. and Carcangiu, G. (2017) Integrated Approach for Post-fire Reinforced Concrete Structures Assessment, Periodica Polytechnica Civil Engineering, 61(4), pp. 677-699.

DOI: https://doi.org/10.3311/PPci.9830.

[7] Fib (CEB-FIP) (2002) Management, maintenance and strengthening of concrete structures.

[8] Valenzuela, S., de Solminihac, H. and Echaveguren, T. (2010). Proposal of an Integrated Index for Prioritization of Bridge Maintenance. Journal of Bridge Engineering, 15(3), pp. 337-343. DOI: 10.1061/(ASCE)BE.1943-5592.0000068.

[9] Liao H.K., Yau N.J. (2011) Development Of Various Bridge Condition Indices For Taiwan Bridge Management System, Proceedings of the 28th ISARC, Seoul, Korea, pp. 911-916. 
[10] Abu Dabous, S. and Alkass, S. (2010). A multi-attribute ranking method for bridge management. Engineering, Construction and Architectural Management, 17(3), pp. 282-291. DOI: 10.1108/09699981011038079

[11] Mistretta F., Piras V., Fadda M.L. (2014) A reliable visual inspection method for the assessment of r.c. structures through fuzzy logic analysis, Proceedings of the 4th International Symposium on Life-Cycle Civil Engineering, pp. 1154-1160.

[12] Fadda M.L., Mistretta F., Piras V. (2014) Vulnerability Assessment of Concrete Bridges using Different Methods of Visual Inspection. Civil-Comp Proceedings, 105, 1759-3433.

[13] Znidaric J., Perus I. (1998), Condition rating methods for concrete structures, CEB Bulletin No. 243: Strategies for Testing and Assessment of Concrete Structures.

[14] Gattulli, V. and Chiaramonte, L. (2005). Condition Assessment by Visual Inspection for a Bridge Management System. Computer-Aided Civil and Infrastructure Engineering, 20(2), pp.95-107.

DOI: $10.1111 /$ j.1467-8667.2005.00379.x.

[15] Kano H., Morikawa H. (2007), Condition rating methodology on RC bridges with chloride induced deterioration, In Reliability and Optimization of Structural Systems: Assessment, Design, and Life-Cycle Performance, Taylor \& Framcis Group, pp. $113-122$

[16] Kušar M., Šelih J., (2014) Analysis of bridge condition on state road network in Slovenia. Journal of the Croatian Association of Civil Engineers, 66(9), pp. 811-822. DOI: 10.14256/JCE.1047.2014

[17] Stochino, F., Fadda, M. and Mistretta, F. (2018). Low cost condition assessment method for existing RC bridges. Engineering Failure Analysis, 86, pp. 56-71. DOI: 10.1016/j.engfailanal.2017.12.021

[18] UNI EN 206-1:2006 Concrete - Part 1: Specification, performance, production and conformity.

[19] Biondini F., Frangopol, D.M. (2018). Life-Cycle Performance of Civil Structure and Infrastructure Systems: Survey, Journal of Structural Engineering (United States), 144(1), art. no. 06017008. DOI: 10.1061/(ASCE)ST.1943-541X.0001923.

[20] Turco E. (2017) Tools for the numerical solution of inverse problems in structural mechanics: review and research perspectives. European Journal of Environmental and Civil Engineering, 21(5), pp. 509-554.

DOI: $10.1080 / 19648189.2015 .1134673$. 